\title{
Stimulation of epithelial repair is a likely mechanism for the action of mifepristone in reducing duration of bleeding in users of progestogen-only contraceptives
}

\author{
Naomi B Morison ${ }^{1}$, Tu'uhevaha J Kaitu'u-Lino ${ }^{1,2}$, Ian S Fraser ${ }^{3}$ and Lois A Salamonsen ${ }^{1}$ \\ ${ }^{1}$ Prince Henry's Institute, Level 4 Block E, Monash Medical Centre, 246 Clayton Rd, Clayton, Victoria 3168 , Australia, \\ ${ }^{2}$ Department of Obstetrics and Gynaecology, Monash University, Clayton, Victoria 3168, Australia and ${ }^{3}$ Sydney \\ Centre for Reproductive Health Research, FPA Health, Ashfield, New South Wales 2131, Australia \\ Correspondence should be addressed to L A Salamonsen; Email: lois.salamonsen@princehenrys.org
}

\begin{abstract}
Many women using progestogen (P)-only contraceptives experience uterine bleeding problems. In clinical trials, a single low dose of mifepristone, given to Implanon users at the beginning of a bleeding episode reduced the number of bleeding days by $\sim 50 \%$ compared with controls. In this study, a single dose of mifepristone was administered to etonogestrel (ENG)-exposed pseudo-pregnant mice, 5 days after artificial decidualization was induced when the endometrium showed signs of bleeding. Control mice received vehicle alone. Mice were culled 12-, 18-, 24- and 48-h post-treatment. In the continued presence of ENG, a single dose of mifepristone stimulated tissue breakdown followed by very rapid repair: most treated tissues were fully restored to the pre-decidualized state by $48 \mathrm{~h}$ post-treatment. During repair, proliferating cells (Ki67 immunostained) were localized to a band of cells around the basal area in breaking down tissues and to the repairing luminal epithelium and glands. Progesterone receptor-positive cells were largely localized to the basal area of the breaking down tissue in treated mice compared with decidual cells in controls. Oestrogen receptor-positive cells were observed in the repairing luminal epithelium and glands compared with the decidua and the basal region in control tissues. It is concluded that mifepristone treatment stimulates rapid restoration of luminal epithelial integrity: such action may be a key event in reducing the number of bleeding days observed in women using Implanon who were treated with a single dose of mifepristone.
\end{abstract}

Reproduction (2008) 136 267-274

\section{Introduction}

Progestogen (P)-only contraceptives (which include the subdermally implantable etonogestrel (ENG)-releasing rod known as Implanon, and Norplant that releases levonorgestrel) are safe and effective methods of fertility regulation for women. Common to all P-only contraceptives and the main reason for discontinuation of their use is the unwanted side effect of break-through bleeding (BTB) where the users experience unpredictable, frequent and often prolonged episodes of bleeding (d'Arcangues 2000). The mechanisms underlying BTB remain largely unknown.

Unlike the bleeding at normal menstruation, which arises predominantly from spiral arterioles in response to falling oestrogen and progesterone levels, the bleeding that occurs in association with the use of P-only contraceptives is largely from small superficial vessels (d'Arcangues 2000). In Norplant users, these vessels appear dilated and thin walled (Hickey et al. 1996) and are increased in number in women with prolonged bleeding (Hickey \& Fraser 2002). Furthermore, vessel support is decreased as observed by a decrease in perivascular smooth muscle $\alpha$-actin (Rogers et al. 2000). Elevated numbers of some leukocyte populations and expression of matrix degrading enzymes, the matrix metalloproteinases, will also contribute to tissue fragility (Vincent et al. 2002). Although the blood arises from the fragile blood vessels, it is clear that epithelial integrity must also be disturbed for vaginal bleeding to occur (Hickey \& Fraser 2002) and indeed, sheets of easily detached surface epithelium are often seen at hysteroscopy (Hickey et al. 1996) in users of P-only contraceptives, suggesting that the epithelium is fragile.

A number of studies in users of depot medroxyprogesterone acetate (DMPA), Norplant and Implanon, have investigated potential treatments for BTB which could provide relief from the bleeding and ultimately lead to an improved continuation rate of P-only contraceptive use. Treatments with anti-inflammatory drugs such as ibuprofen or mefenamic acid (Archer et al. 1996, Kaewrudee et al. 1999) or ethinyl oestradiol (EE) (Witjaksono et al. 1996) have had only small effects on the duration of a bleeding episode. Importantly, treatment with EE renders the idea of a progestogen only and therefore oestrogen-free 
contraceptive regime futile. By contrast, short-term administration of the anti-progestogen, mifepristone, has been successful in reducing bleeding days in women using P-only contraception in a number of independent studies (Cheng et al. 2000, Glasier et al. 2002, Jain et al. 2003, Massai et al. 2004, Weisberg et al. 2006). A further reduction in the bleeding days was observed upon mifepristone treatment in conjunction with oestrogen (Weisberg et al. 2006). Examination of endometrium following such short-term treatment in the continued presence of progestogen showed increased endometrial proliferation and decreased stromal apoptosis along with increased steroid hormone receptors oestrogen receptor- $\alpha$ $(\mathrm{ER} \alpha)$, progesterone receptor (PR-A, PR-B) and the steroid receptor SRC-1 (Jain et al. 2006, 2007) in users of DMPA, while in Norplant users, a single dose of mifepristone up-regulated ER and down-regulated PR subtype B in both glands and stroma (Glasier et al. 2002), consistent with functional inhibition of progesterone.

We recently described a mouse model in which ENG was administered long term to animals that were induced artificially to undergo decidualization in one uterine horn. Examination of endometrial morphology showed that large blood vessels developed and subsequently tissue integrity was reduced in the decidualized uterine horn: this was followed by tissue breakdown and eventual repair (Morison et al. 2007). This model thus provides an opportunity for functional studies to examine the mechanisms of action of treatment modalities for the bleeding.

The aim of the present study was to use this mouse model to elucidate the mechanisms by which mifepristone acts to reduce the number of bleeding days in the continued presence of progestogens such as ENG (Weisberg et al. 2006) in women. We administered a single dose of mifepristone at a time of endometrial instability to the mouse model for long-term ENG exposure (Morison et al. 2007), and examined the endometrium at a number of time points following treatment to determine morphological changes, including epithelial repair, along with alterations in cellular proliferation markers and steroid receptor expression. The data suggest that mifepristone acts by exacerbating the endometrial fragility sufficiently to stimulate repair mechanisms, particularly restoration of an intact luminal epithelium.

\section{Results} Morphology of the endometrium following injection of
mifepristone

Morphology of cross-sections of endometrium was assessed 12, 18, 24 and $48 \mathrm{~h}$ after mifepristone treatment and compared with that of untreated (control; no mifepristone) animals at 0 and $48 \mathrm{~h}$. Control animals at $0 \mathrm{~h}$ had a highly decidualized endometrium containing many blood vessels and a closure of the lumen as described previously (Morison et al. 2007; Fig. 1). By contrast, in mifepristone-treated animals, by $12 \mathrm{~h}$ the decidualized zone had undergone massive breakdown and in some tissues there was evidence of re-epithelialization (Fig. 2). Similar morphologies were observed $18 \mathrm{~h}$ after mifepristone treatment. Twenty-four hours after treatment the majority of tissues showed substantial re-epithelialization. In some cases, the epithelium had completely repaired, isolating the decidua within the newly formed lumen. Forty-eight hours after mifepristone treatment the endometrium was completely repaired in $>90 \%$ of tissues, with full restoration of glandular and luminal epithelium and the stromal compartment (Fig. 2). In some cases, the shed decidua remained surrounded by the newly formed epithelium. The epithelial regeneration always originated from the mesometrial side of the tissue in the basal region between the decidua and newly forming stroma (Fig. 2). In many cases, at each time point there was a basal ring of tightly packed cells forming an intensely stained band around the decidua. In comparison, endometrium from control (Implanon, no mifepristone) animals at $48 \mathrm{~h}$ contained large blood vessels containing red blood cells. There was no evidence of tissue repair (Fig. 1) in control animals.

\section{Morphology of the endometrium following injection of mifepristone plus oestradiol}

Mifepristone was also used in conjunction with a single dose of oestradiol (250 ng) administered $6 \mathrm{~h}$ later. At both 18 and $24 \mathrm{~h}$ post-treatment, the extent of breakdown and repair was similar to that in the mifepristoneonly group (data not shown). In all treatment groups, there was considerable variation between animals.
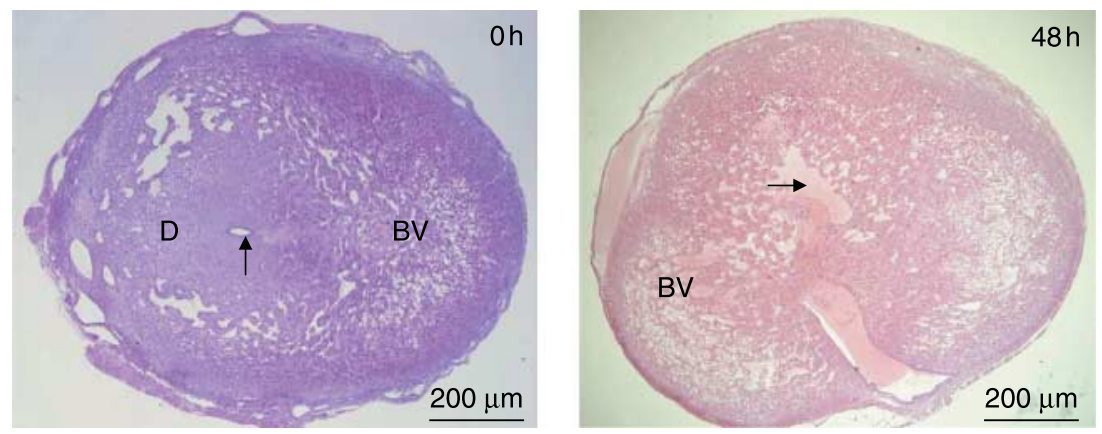

Figure 1 Haematoxylin and eosin staining of endometrium from control animals at 0 and $48 \mathrm{~h}$ after vehicle injection. At $0 \mathrm{~h}$, there is closure of the lumen (arrow) and the tissue is highly decidualized (D) with many blood vessels (BV). At $48 \mathrm{~h}$, blood vessels are prevalent and there is some tissue breakdown. The tissue contains many red blood cells (arrow). 

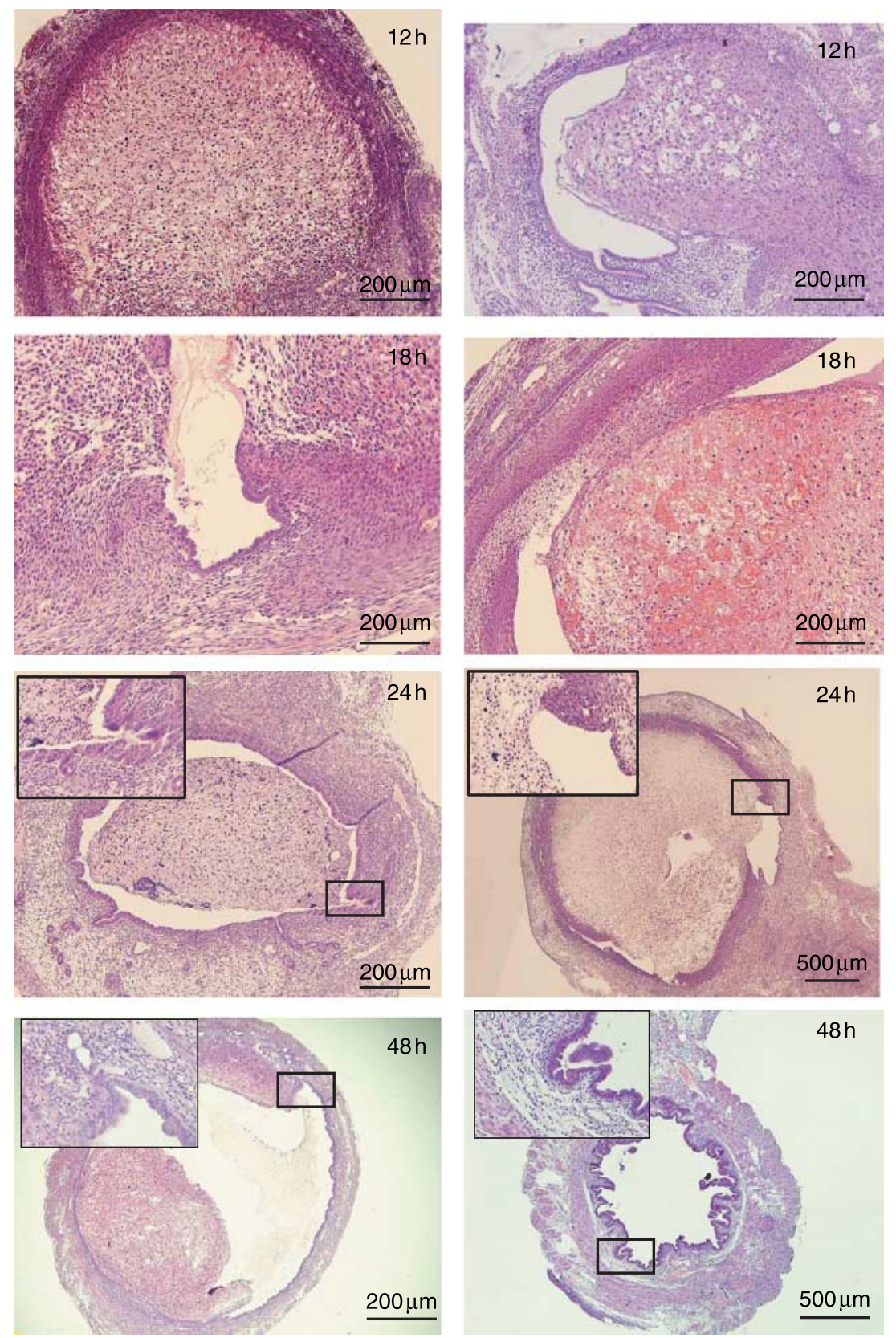

Figure 2 Haematoxylin and eosin staining of endometrium collected from mifepristone treated animals 12, 18, 24 and $48 \mathrm{~h}$ after injections. Two examples are shown for each time point with insets showing higher powered images. Evidence of tissue breakdown and repair was observed in some tissues at $12 \mathrm{~h}$ progressing further over time. Many tissues were fully repaired by $24 \mathrm{~h}$. By $48 \mathrm{~h}$, the majority of tissues had fully repaired with complete regeneration of the stromal and epithelial compartments.

\section{Epithelial regeneration}

The extent of epithelial repair was clearly identified by immunostaining for cytokeratin (Fig. 3A). In some cases, epithelial staining was observed by $12 \mathrm{~h}$ after the mifepristone injection: in other instances, there was no epithelial re-growth at this time and only residual epithelium was stained, similar to controls at $0 \mathrm{~h}$. As the endometrium of treated animals underwent breakdown and repair, the epithelial regeneration proceeded, segregating the basal zone from the decidual zone. To determine the extent of epithelial repair, cytokeratin staining was analysed using the analySIS
Soft Imaging System. The brown cytokeratin staining and the background blue haematoxylin staining were detected as two different particles (designated by the program) and the brown staining particles were determined as a percentage of the total. At $0 \mathrm{~h}$, control sections had $<10 \%$ cytokeratin staining (of original epithelium remaining following decidualization (Fig. 3B)). At $48 \mathrm{~h}$, the control animals had a similar percentage of staining compared with $0 \mathrm{~h}$ controls. The mifepristone-treated animals at 12 and $18 \mathrm{~h}$ also showed similar staining compared with controls. However, at 24 and $48 \mathrm{~h}$ post-mifepristone, the percentage of cytokeratin staining had more than doubled (Fig. 3A and B), 

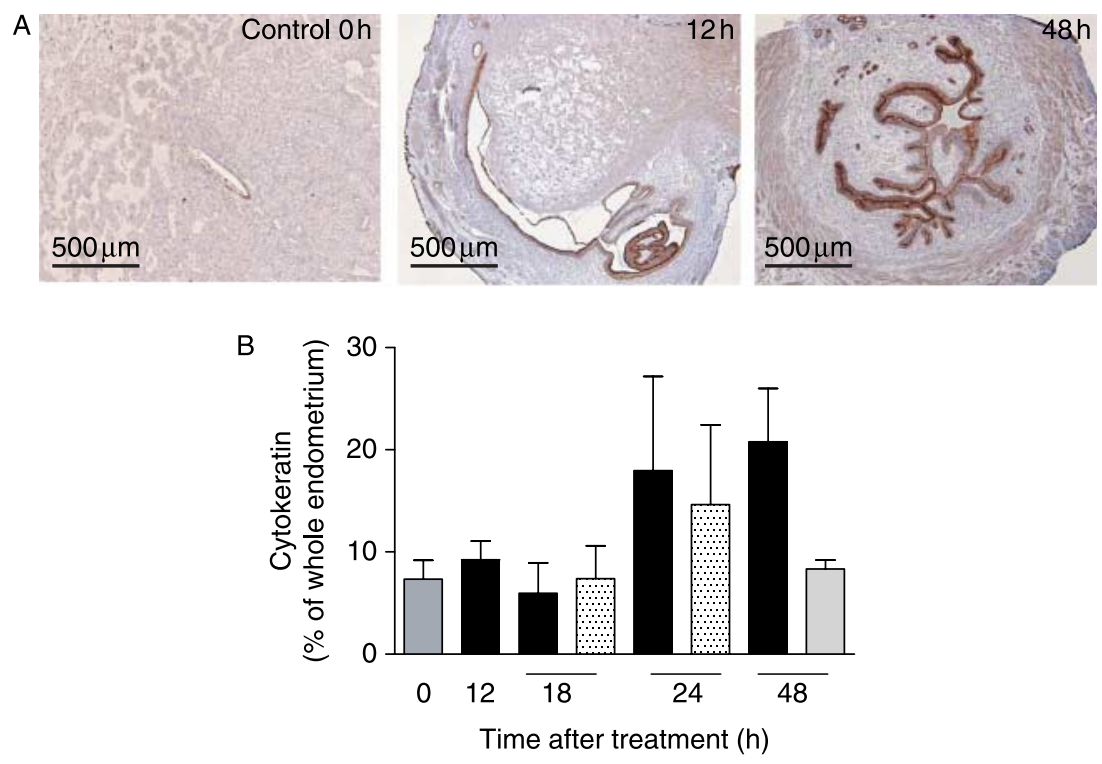

Figure 3 (A) Cytokeratin staining (brown) of epithelial cells in control $(0 \mathrm{~h})$ and mifepristonetreated mice. Very little staining is observed in control tissue at $\mathrm{O} \mathrm{h}$ with increasing staining observed as the luminal and glandular epithelium are restored over time. (B) Cytokeratin staining expressed as a percentage of total stain (cytokeratin plus haematoxylin) within the endometrium of control (grey bars), mifepristone alone (black bars) and mifepristone plus oestrogen (dotted bars) treated animals.

although this did not reach significance due to the variability between animals. Endometrium from animals treated with mifepristone plus oestrogen showed similar cytokeratin staining to mifepristone treatment alone at 18 and $24 \mathrm{~h}$ post-treatment (Fig. 3B). Subsequent analyses were therefore assessed according to endometrial morphology rather than treatment time point.

\section{Proliferation of the cellular compartments post- mifepristone treatment}

To determine the cellular components responsible for the tissue repair, Ki67 was used as a marker for proliferating cells. Analysis was based on the morphology of the tissue (intact decidua, breaking down decidua, breaking down with evidence of repair, fully repaired). Ki67-positive cells were initially detected in the decidua (Fig. 4A) but once tissue was breaking down, stained cells were predominantly in the basal area (Fig. 4B). In tissue undergoing repair, Ki67-positive cells were primarily in regenerating epithelium (Fig. 4B and C), although isolated positive cells were seen within the regenerated stroma (Fig. 4C). These results are summarized in Table 1.

\section{Progesterone receptor localization}

Mifepristone is a progesterone antagonist acting via its high affinity binding to the PR. Cellular localization of PR was analysed in control and mifepristone-treated animals. There was very little PR staining in decidualized stromal cells from either group. PR was localized within areas of tissue breakdown in control animals (Fig. 5A) and differed from those in mifepristone-treated animals where PR was largely localized in basal cells in the tissue undergoing breakdown (Fig. 5B). In repairing tissue after mifepristone treatment, PR-positive staining was observed in some sub-epithelial stromal cells with little staining in other cellular compartments (Fig. 5B). The results are summarized in Table 1.

\section{Oestrogen receptor localization}

Mifepristone has effects on endometrial ER in women (Glasier et al. 2002, Jain et al. 2007). In the mifepristonetreated mice, there was strong staining for ER in decidual cells in control animals but very little in breaking down tissue (Fig. 6A), except in the basal region. However, in the repairing endometrium, ER-positive cells were
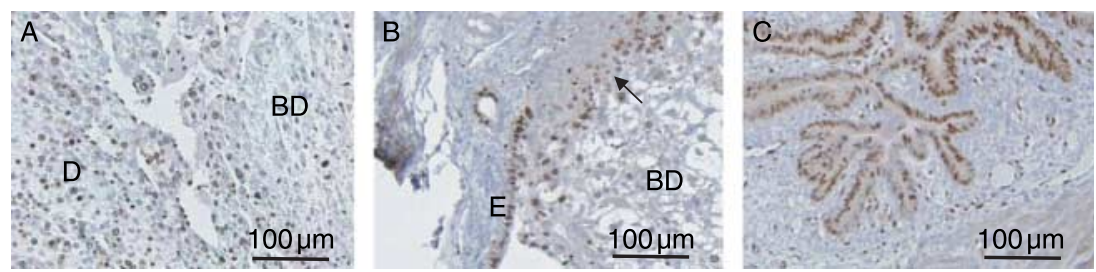

Figure 4 Immunohistochemical staining of Ki67-positive proliferating cells in endometrium from mifepristone-treated mice. Positive staining (brown) was observed in many cells within the decidua (A) and the basal area (B, arrow) of breaking down tissue. Regenerating luminal and glandular epithelium also contained high numbers of Ki67-positive cells (B). Positive staining was observed largely within the luminal epithelium and glands of fully repaired tissue, with some isolated cells seen within the stroma (C). BD, breakdown; D, decidua; E, epithelium. 
Table 1 A summary of Ki67, progesterone receptor (PR) and oestrogen receptor (ER) staining in the endometrium of control and mifepristone-treated mice.

\begin{tabular}{|c|c|c|c|c|c|c|}
\hline Marker & Treatment group & Intact decidua & Breaking down decidua & Repairing epithelium & Glands & New stroma \\
\hline Ki67 & Treatment & ++ & +++ basal & +++ & +++ & + \\
\hline PR & Control & + & +++ & N/A & N/A & N/A \\
\hline PR & Treatment & + & +++ basal & - & - & + Sub-luminal \\
\hline ER & Control & +++ & +++ basal & N/A & N/A & N/A \\
\hline ER & Treatment & +++ & +++ basal & ++ & ++ & + Sub-luminal \\
\hline
\end{tabular}

Tissue was analysed based on endometrial morphology and subcellular compartments (intact decidua, breaking down, repairing luminal epithelium, glands and new stromal cells). The relative numbers of positively stained cells within each subcellular compartment are shown; -, no positive cells; + , a few positive cells; +++ , very high numbers of positive cells; N/A, not applicable.

seen in the regenerating luminal and glandular epithelium (Fig. 6B) and in isolated sub-epithelial stromal cells (Fig. 6B). These results are summarized in Table 1.

\section{Discussion}

In this study, we used a previously described mouse model of long-term ENG exposure (Morison et al. 2007) in functional studies to elucidate potential mechanisms underlying the successful use of mifepristone as a treatment for BTB in women. The results show that, in most mice, complete endometrial breakdown and repair occurs within $48 \mathrm{~h}$ of mifepristone administration with rapid restoration of an intact luminal epithelium. We also show that while some proliferation occurs within the decidua, most is seen within the basal region below the area of tissue breakdown as well as in the repairing luminal epithelium and glands. As previously described, $\mathrm{PR}$ are present in scattered cells throughout the decidua in non-treated control endometrium but are up-regulated
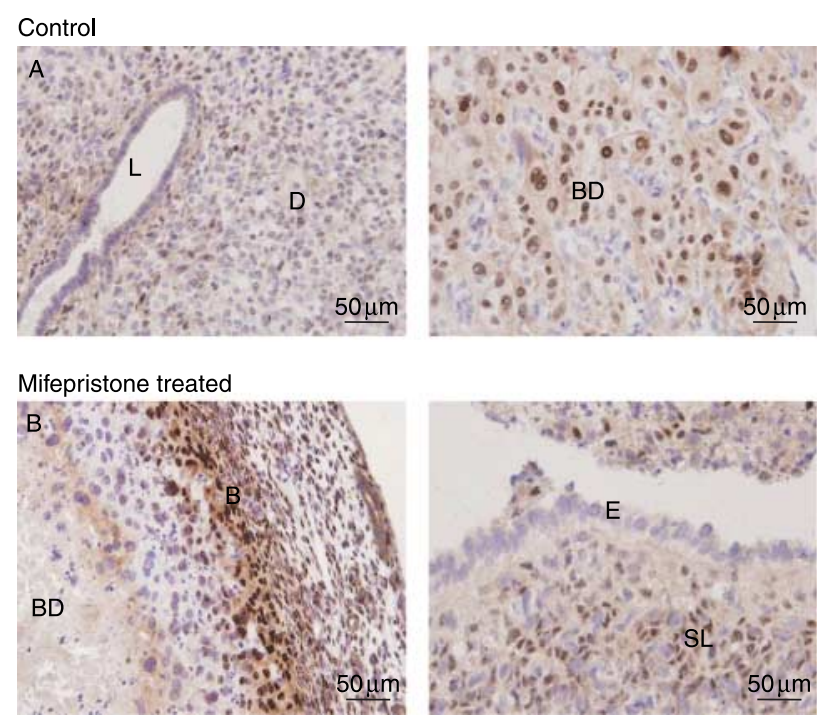

Figure 5 Immunohistochemical localization of progesterone receptor (PR) expression in endometrium from control (A) and mifepristonetreated (B) mice. In control animals, positive staining was observed in some isolated decidual cells (D) and was highly expressed in breaking down (BD) tissue. In tissues undergoing breakdown and repair following mifepristone treatment, positive PR staining was observed in the basal area of breaking down tissue and in isolated subluminal (SL) stromal cells. E, epithelium; L, lumen. during endometrial breakdown (Morison et al. 2007). However, after mifepristone treatment, PR are highly expressed in cells in the basal region of the breaking down and repairing tissue although not in the repairing or fully repaired epithelium. The pattern of ER also changes in the repairing endometrium after mifepristone treatment where positive staining is located in the regenerating luminal epithelium and glands.

To date, mifepristone has largely been used in the termination of pregnancies and as an emergency contraceptive (Jain et al. 2002, Honkanen et al. 2004, Jin et al. 2005). However, when administered in the luteal phase of the menstrual cycle, mifepristone induces a 'menses' like response in women (Critchley et al. 2003), a characteristic similarly observed when artificially 'cycling' non-human primates are treated with antiprogestogens (Slayden \& Brenner 2004). The potential of mifepristone to treat BTB associated with P-only contraceptives has also been explored (Massai et al. 2004). A recent clinical trial in Australia has shown that a single
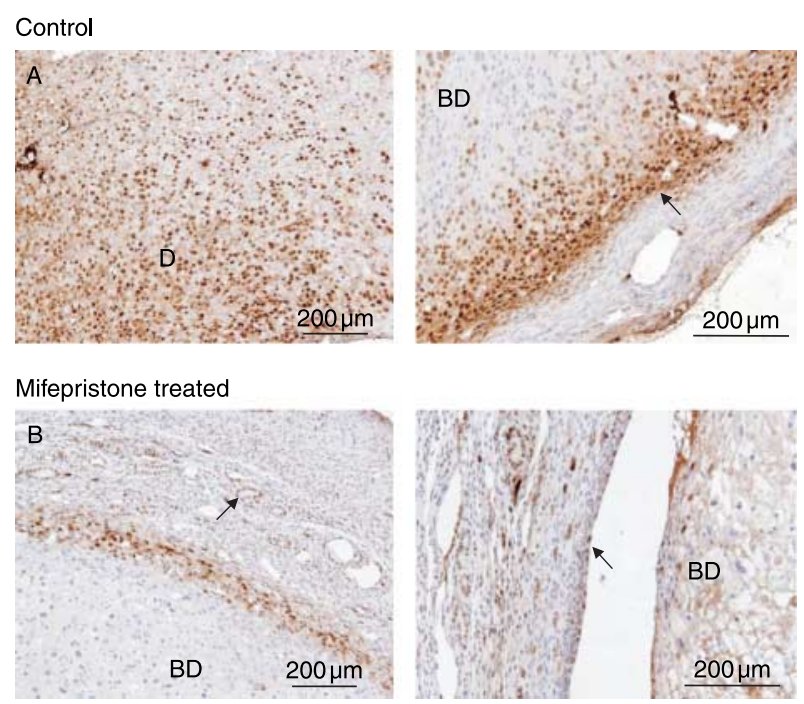

Figure 6 Immunohistochemical localization of oestrogen receptor expression in endometrium from control (A) and mifepristone-treated (B) mice. In control animals, large numbers of positive cells were observed in the decidua (D) and were also isolated to the basal region (arrow) of breaking down (BD) tissue. In tissues undergoing breakdown and repair following mifepristone treatment (B) positive ER staining was observed in the basal area of breaking down tissue and in regenerating luminal and glandular epithelial cells (arrows). 
low dose of mifepristone reduces the number of days of a bleeding episode when administered to Implanon users early within this episode (Weisberg et al. 2006), supporting earlier studies in Chinese women using Norplant and complaining of frequent and irregular bleeding. In these women, a single monthly dose of mifepristone reduced the length of bleeding episodes over a 90-d treatment period (Cheng et al. 2000). Although the mechanisms by which anti-progestogens reduce bleeding episodes has not been understood, the functional experiments described in the present study suggest that mifepristone, by stimulating tissue breakdown, induces very rapid repair, particularly re-epithelialization of the endometrium, thus restoring epithelial integrity and stopping the bleeding.

Previous studies have shown alterations in PR and ER after short-term treatment with mifepristone in women using P-only contraceptives. In Norplant users, a single dose of mifepristone administered at the start of a bleeding episode resulted in increased ER and decreased PR-B in both the stroma and glands (Glasier et al. 2002). Although the antibody used in the present studies detected both PR-A and PR-B, our results are in overall agreement with the previous findings. Furthermore, increases in ER $\alpha$ and $E R \beta$ and also PR-A and PR-B were observed in both the glands and stroma after mifepristone treatment of new users of DMPA 1 week after treatment (Jain et al. 2007). These results contrast with the present studies in which PR was not detected in the luminal or glandular epithelium after mifepristone treatment. However, our analyses were performed at $48 \mathrm{~h}$ after mifepristone treatment, whereas Jain et al. (2007) analysed tissue 1 week after treatment. There may also be a difference between mice and women.

There are a limited number of studies using mifepristone in rodents. When four daily treatments of mifepristone were administered to pseudo-pregnant rats from day 5 of pseudo-pregnancy, PR (Pgr) mRNA in whole uterine tissue was decreased on day 9 (Spencer et al. 2001). Likewise, in pregnant rats (Ogle et al. 1998) following a single dose of mifepristone administered on day 9 of pregnancy, both PR-A and PR-B mRNA decreased significantly in the whole uterine tissue 12 and $24 \mathrm{~h}$ after treatment. However, neither study examined the cellular location of PR and it is therefore possible that the reduced mRNA reflected epithelial PR expression levels, as in our studies.

The endometrial changes in response to mifepristone treatment in the present study were rapid with full breakdown and regeneration of the tissue observed within $48 \mathrm{~h}$ of treatment in spite of continuing ENG administration. Mifepristone treatment causes a pharmacological drop in progestogen support, so it is perhaps not surprising that its effects mimic our previous studies with a mouse model for menstruation. In these mice, the endometrium has likewise undergone complete breakdown and repair $48 \mathrm{~h}$ after withdrawal of progesterone support (Brasted et al. 2003, Kaitu'u et al. 2005).
It is likely that an important feature of abnormal endometrial bleeding in women using P-only contraceptives is a compromised or fragile epithelium. Indeed, in women using Norplant, the endometrium displays reduced epithelial cytokeratin staining with more rounded epithelial cells compared with control biopsies (Wonodirekso et al. 1996, 2000). Thus, the restoration of the epithelial surface would have the potential to terminate a bleeding episode. In this study, we observed for the first time very rapid restoration of the epithelium after mifepristone treatment, as indicated by the Ki67 staining. This repair was observed as early as $12 \mathrm{~h}$ postmifepristone treatment, and we suggest that such repair is likely to be the key to the success of the treatment trial in women (Weisberg et al. 2006). Surprisingly, in contrast to the clinical trial, we did not observe any significant differences between mifepristone treatment alone or in conjunction with oestrogen, although it is possible that subtle differences were not detected at the time points selected. Our results indicating an increase in epithelial proliferation are in agreement with previous observations of increased Ki67-positive cells in the endometrium of new DMPA users treated for 1 week with mifepristone (Jain et al. 2007). This increase was greater in the glandular epithelium compared with the stroma, similar to the results we obtained with the mouse model.

In summary, we have shown here for the first time in vivo that a single dose of mifepristone in the presence of Implanon causes rapid tissue breakdown and repair in this mouse model, and we propose that the restoration of the integrity of the luminal epithelium is the key event in reducing the number of bleeding days observed in Implanon users who were treated with mifepristone.

While clinical trials have focused on the potential of mifepristone as a treatment for BTB, studies in women are restricted in their ability to assess the holistic changes in such a dynamic tissue. Our mouse model offered a unique opportunity to study endometrial changes in vivo, in response to mifepristone treatment and has identified some key elements underlying its success.

\section{Materials and Methods}

\section{Animals}

Female C57BL/6 mice, age 8-12 weeks, were obtained from Monash University Animal Services and housed under standard conditions with food and water provided ad libitum and a constant light cycle of $12 \mathrm{~h}$ (lights on from 0800 to $2000 \mathrm{~h}$ ). Ethics approval was granted by the Monash University/Monash Medical Centre Animal Ethics Committee B.

\section{Mouse model for long-term progesterone exposure}

A previously described mouse model for long-term progestogen exposure (slightly modified to simplify the procedure; Morison et al. 2007) was used to determine the effects of a single dose of 
mifepristone on endometrial breakdown and repair in the continued presence of ENG. Briefly, intact female mice were mated with vasectomized males to induce a pseudo-pregnant state. Three or four days after the seminal plug was found, one sixteenth of a standard Implanon rod (containing ENG; gift from Organon, Oss, The Netherlands) encased in a silastic implant (0.062 inches internal diameter; Dow Corning, Midland, MI, USA: functional size $1 \mathrm{~cm}$ length (Kaitu'u et al. 2005)) was inserted subcutaneously into the back of the animals. Simultaneously, the mice received a single injection of sesame oil $(20 \mu \mathrm{l})$ into the lumen of one uterine horn to induce artificial decidualization (stimulated horn). The other horn was left untreated (non-stimulated horn). The time of decidual stimulus was designated day $0(0 \mathrm{~d})$. Two days later the injected horn had undergone extensive decidualization. Mice were injected with mifepristone (see below) at $5 \mathrm{~d}(\mathrm{O} h)$ and uteri were collected over the subsequent $48 \mathrm{~h}$ ( $n \geq 3$ at each time point). Figure 7 details the treatment regime. All surgeries were performed under xylazine/ ketamine-induced anaesthesia.

\section{Mifepristone and oestrogen treatment}

Mifepristone tablets (25 mg; Hualin Company, Shanghai, China) were crushed, reconstituted in methanol and then stored at $20{ }^{\circ} \mathrm{C}$ until use. A single dose of mifepristone $(200 \mu \mathrm{g}$ diluted in $100 \mu \mathrm{l}$ arachis oil) was injected subcutaneously at $5 \mathrm{~d}$. Methanol diluted in arachis oil was injected as control. Since a previous clinical trial in women showed that mifepristone in conjunction with oestrogen was more successful in stopping a bleeding episode than mifepristone alone, a second group of animals received mifepristone as above and $17 \beta$-oestradiol (250 ng in $100 \mu \mathrm{l}$ arachis oil) or control $(100 \mu \mathrm{l}$ arachis oil) administered $6 \mathrm{~h}$ after mifepristone treatment.

\section{Tissue collection}

Uteri were cleaned of fat, weighed and each horn cut into four pieces that were fixed overnight at $4{ }^{\circ} \mathrm{C}$ in phosphate-buffered formalin, or for $2 \mathrm{~h}$ at room temperature in Carnoy's fixative. Formalin- and Carnoy's-fixed tissues were subsequently processed to wax.

\section{Histology and immunohistochemistry}

Uterine cross-sections ( $5 \mu \mathrm{m}$ ) offormalin- or Carnoy's-fixed tissue were processed through Histosol (Sigma) and a graded series of

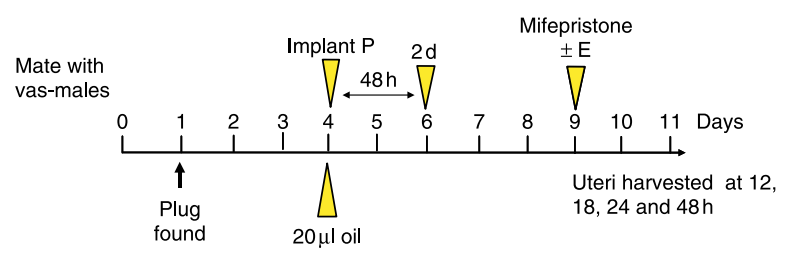

Figure 7 Time line of the treatment regime administered to the mice. Intact female mice were mated with vasectomized (vas-) males to induce pseudo-pregnancy. Mice then received an injection of sesame oil (decidual stimulus) into one uterine horn and one sixteenth of an Implanon rod (P). Mifepristone was administered 5 days later $(0 \mathrm{~h})$ followed $6 \mathrm{~h}$ later by oestrogen $(\mathrm{E})$ in one group. Animals were killed up to $48 \mathrm{~h}$ after mifepristone treatment and uteri harvested. ethanol, to distilled water $\left(\mathrm{dH}_{2} \mathrm{O}\right)$ prior to immunostaining or histological staining. For histological analysis, hydrated sections were stained with haematoxylin and eosin using standard staining procedures and mounted using dibutyl polystyrene xylene (DPX; BDH Laboratory Supplies, Poole, England).

Immunolocalization of epithelial cells was performed using rabbit anti-cytokeratin, $\mathrm{H}-240$ (rabbit polyclonal IgG; Santa Cruz Biotechnology, Santa Cruz, CA, USA) diluted to $4 \mu \mathrm{g} / \mathrm{ml}$ in Tris-buffered saline (TBS). Antigen retrieval was performed on Carnoy's-fixed tissue by heating sections in $0.1 \mathrm{M}$ citrate buffer for $5 \mathrm{~min}$ in a $700 \mathrm{~W}$ microwave set to high. Endogenous peroxidase activity was quenched by immersion of sections in $3 \% \mathrm{v} / \mathrm{v}_{2} \mathrm{O}_{2}$ in methanol for $10 \mathrm{~min}$ at RT. Sections were then incubated with blocking solution containing $10 \% \mathrm{v} / \mathrm{v}$ normal goat serum in TBS for 20 min at RT. Primary antibody or rabbit IgG control was incubated with tissues for $1 \mathrm{~h}$ at RT prior to washing in $0.6 \% \mathrm{v} / \mathrm{v}$ Tween $20 / \mathrm{TBS}$ and incubating with biotinylated goat anti-rabbit IgG (1:200; Dako, Glostrup, Denmark) for $30 \mathrm{~min}$ at RT.

Proliferating cells were immunodetected using rabbit anti-Ki67 (polyclonal; Novacastra, Newcastle upon Tyne, UK) at $0.15 \mu \mathrm{g} / \mathrm{ml}$ in $1 \% \mathrm{v} / \mathrm{v}$ foetal calf serum (FBS)/TBS. Antigen retrieval on Carnoy's-fixed tissue was performed by heating sections in $0.1 \mathrm{M}$ citrate buffer for $5 \mathrm{~min}$ in a $700 \mathrm{~W}$ microwave set to high followed by $5 \mathrm{~min}$ set to medium. Endogenous per oxidase activity was quenched by immersion of sections in $3 \% \mathrm{v} / \mathrm{v}$ $\mathrm{H}_{2} \mathrm{O}_{2}$ in methanol for 10 min at RT. Sections were then incubated with blocking solution containing $10 \% \mathrm{v} / \mathrm{v}$ normal goat serum in TBS for 30 min at RT. Primary antibody or rabbit IgG control (diluted to the same final concentration) was incubated with tissues for $1 \mathrm{~h}$ at RT prior to washing in TBS and incubating with biotinylated goat anti-rabbit IgG (1:200, Dako) for 30 min at RT.

For the above protocols, the StrepABC horse radish peroxidase (HRP) kit and diaminobenzidine (DAB; Dako) solution were used in accordance with the manufacturer's specifications to reveal the staining.

Immunolocalization of progesterone receptor (PR-A and PR-B) was performed using the rabbit anti-mouse polyclonal antibody (PR-A and PR-B, C-20:sc-593; Santa Cruz Biotechnology). Endogenous peroxidase activity was quenched in formalinfixed sections ( $3 \% \mathrm{v} / \mathrm{v} \mathrm{H}_{2} \mathrm{O}_{2}$ in methanol for $10 \mathrm{~min}$ ) followed by antigen retrieval $(0.1 \%$ trypsin in $0.1 \% \mathrm{w} / \mathrm{v}$ calcium chloride for $30 \mathrm{~min}$ at RT) and blocking in 20\% v/v normal goat serum/TBS for $10 \mathrm{~min}$ at RT. Sections were then incubated with primary antibody $(2 \mu \mathrm{g} / \mathrm{ml})$ for $1 \mathrm{~h}$ at $37^{\circ} \mathrm{C}$ and washed with $0.6 \% \mathrm{v} / \mathrm{v}$ Tween 20/TBS, and then incubated with goat anti-rabbit HRP (Polymer, Dako Envision + kit) for $30 \mathrm{~min}$ at RT and visualized using DAB for $3 \mathrm{~min}$.

Immunolocalization of oestrogen receptor- $\alpha(E R \alpha)$ was performed using an affinity purified rabbit anti-human polyclonal antibody (H-20:sc-543; Santa Cruz Biotechnology). Carnoy'sfixed tissues were subjected to antigen retrieval $(3 \mathrm{~min}$ at high, $5 \mathrm{~min}$ at medium and then $1 \mathrm{~min}$ at high level in a $700 \mathrm{~W}$ microwave in $0.1 \mathrm{M}$ citrate buffer) followed by quenching of endogenous peroxidase activity $\left(3 \% \mathrm{v} / \mathrm{v} \mathrm{H}_{2} \mathrm{O}_{2}\right.$ in methanol for $10 \mathrm{~min}$ at RT) and blocking (20\% v/v normal goat serum/TBS $10 \mathrm{~min}$ at RT). Primary antibody $(2 \mu \mathrm{g} / \mathrm{ml})$ was incubated with the tissues for $60 \mathrm{~min}$ at $37^{\circ} \mathrm{C}$. Goat anti-rabbit/HRP-conjugated 
polymer (DAKO EnVision + System Kit) was then incubated with the tissue for $30 \mathrm{~min}$ at RT and visualized using DAB for $2 \mathrm{~min}$.

\section{Quantitation of cytokeratin staining}

Cytokeratin staining was quantitated using the analySIS Soft Imaging Software (Olympus, Mt Waverley, Victoria, Australia). The cytokeratin (brown, immunostaining) and haematoxylin (blue, histochemical) stains were detected as different particles (as designated by the software) within each tissue section. The amount of brown (cytokeratin) particles was determined as a percentage of the total ( $n=3-5$ per time point). Statistical differences were determined using Kruskal-Wallis one-way ANOVA (GraphPad PRISM; Graphpad Software Inc., La Jolla, CA, USA).

\section{Declaration of interest}

The authors declare that there is no conflict of interest that would prejudice the impartiality of this scientific work.

\section{Funding}

This study was funded by the National Institutes of Health (HD43192), the National Health and Medical Research Council of Australia (\#388901 to LAS) and an Australian Postgraduate Association scholarship (to T J K-L).

\section{Acknowledgements}

We thank Dr Devora Lieberman of Organon for the provision of the Implanon rods.

\section{References}

Archer DF, Philput CA \& Weber ME 1996 Management of irregular uterine bleeding and spotting associated with Norplant. Human Reproduction 11 (Supplement 2) 24-30.

Brasted M, White CA, Kennedy TG \& Salamonsen LA 2003 Mimicking the events of menstruation in the murine uterus. Biology of Reproduction 69 1273-1280.

Cheng L, Zhu H, Wang A, Ren F, Chen J \& Glasier A 2000 Once a month administration of mifepristone improves bleeding patterns in women using subdermal contraceptive implants releasing levonorgestrel. Human Reproduction 15 1969-1972.

Critchley HO, Kelly RW, Brenner RM \& Baird DT 2003 Antiprogestins as a model for progesterone withdrawal. Steroids 68 1061-1068.

d'Arcangues C 2000 Management of vaginal bleeding irregularities induced by progestin-only contraceptives. Human Reproduction 15 (Supplement 3) 24-29.

Glasier AF, Wang H, Davie JE, Kelly RW \& Critchley HO 2002 Administration of an antiprogesterone up-regulates estrogen receptors in the endometrium of women using Norplant: a pilot study. Fertility and Sterility 77 366-372.

Hickey M \& Fraser IS 2002 Surface vascularization and endometrial appearance in women with menorrhagia or using levonorgestrel contraceptive implants. Implications for the mechanisms of breakthrough bleeding. Human Reproduction 17 2428-2434.

Hickey M, Fraser I, Dwarte D \& Graham S 1996 Endometrial vasculature in Norplant users: preliminary results from a hysteroscopic study. Human Reproduction 11 (Supplement 2) 35-44.

Honkanen H, Piaggio G, Hertzen H, Bartfai G, Erdenetungalag R, Gemzell-Danielsson K, Gopalan S, Horga M, Jerve F, Mittal S et al. 2004 WHO multinational study of three misoprostol regimens after mifepristone for early medical abortion. British Journal of Obstetrics and Gynaecology 111 715-725.

Jain JK, Dutton C, Harwood B, Meckstroth KR \& Mishell DR Jr 2002 A prospective randomized, double-blinded, placebo-controlled trial comparing mifepristone and vaginal misoprostol to vaginal misoprostol alone for elective termination of early pregnancy. Human Reproduction 17 1477-1482.

Jain JK, Nicosia AF, Nucatola DL, Lu JJ, Kuo J \& Felix JC 2003 Mifepristone for the prevention of breakthrough bleeding in new starters of depomedroxyprogesterone acetate. Steroids 68 1115-1119.

Jain JK, Li A, Yang W, Minoo P \& Felix JC 2006 Effects of mifepristone on proliferation and apoptosis of human endometrium in new users of medroxyprogesterone acetate. Human Reproduction 21 798-809.

Jain JK, Li A, Yang W, Minoo P \& Felix JC 2007 Mifepristone alters expression of endometrial steroid receptors and their cofactors in new users of medroxyprogesterone acetate. Fertility and Sterility 87 8-23.

Jin J, Weisberg E \& Fraser IS 2005 Comparison of three single doses of mifepristone as emergency contraception: a randomised controlled trial. Australian and New Zealand Journal of Obstetrics and Gynaecology 45 489-494.

Kaewrudee S, Taneepanichskul S, Jaisamraun U \& Reinprayoon D 1999 The effect of mefenamic acid on controlling irregular uterine bleeding secondary to Norplant use. Contraception 60 25-30.

Kaitu'u TJ, Shen J, Zhang J, Morison NB \& Salamonsen LA 2005 Matrix metalloproteinases in endometrial breakdown and repair: functional significance in a mouse model. Biology of Reproduction 73 672-680.

Massai MR, Pavez M, Fuentealba B, Croxatto HB \& d'Arcangues C 2004 Effect of intermittent treatment with mifepristone on bleeding patterns in Norplant implant users. Contraception 70 47-54.

Morison NB, Zhang J, Kaitu'u-Lino TJ, Fraser IS \& Salamonsen LA 2007 The long-term actions of etonogestrel and levonorgestrel on decidualized and non-decidualized endometrium in a mouse model mimic some effects of progestogen-only contraceptives in women. Reproduction 133 309-321.

Ogle TF, Dai D, George P \& Mahesh VB 1998 Regulation of the progesterone receptor and estrogen receptor in decidua basalis by progesterone and estradiol during pregnancy. Biology of Reproduction 58 1188-1198.

Rogers PA, Plunkett D \& Affandi B 2000 Perivascular smooth muscle alphaactin is reduced in the endometrium of women with progestin-only contraceptive breakthrough bleeding. Human Reproduction $\mathbf{1 5}$ (Supplement 3) 78-84.

Slayden OD \& Brenner RM 2004 Hormonal regulation and localization of estrogen, progestin and androgen receptors in the endometrium of nonhuman primates: effects of progesterone receptor antagonists. Archives of Histology and Cytology 67 393-409.

Spencer F, Chi L \& Zhu M 2001 Temporal relationships among uterine pituitary adenylate cyclase-activating polypeptide, decidual prolactinrelated protein and progesterone receptor mRNAs expressions during decidualization and gestation in rats. Comparative Biochemistry and Physiology. Toxicology \& Pharmacology 129 25-34.

Vincent AJ, Zhang J, Ostor A, Rogers PA, Affandi B, Kovacs G \& Salamonsen LA 2002 Decreased tissue inhibitor of metalloproteinase in the endometrium of women using depot medroxyprogesterone acetate: a role for altered endometrial matrix metalloproteinase/tissue inhibitor of metalloproteinase balance in the pathogenesis of abnormal uterine bleeding? Human Reproduction 17 1189-1198.

Weisberg E, Hickey M, Palmer D, O'Connor V, Salamonsen LA, Findlay JK \& Fraser IS 2006 A pilot study to assess the effect of three short-term treatments on frequent and/or prolonged bleeding compared to placebo in women using Implanon. Human Reproduction 21 295-302.

Witjaksono J, Lau TM, Affandi B \& Rogers PA 1996 Oestrogen treatment for increased bleeding in Norplant users: preliminary results. Human Reproduction 11 (Supplement 2) 109-114.

Wonodirekso S, Hadisaputra W, Affandi B, Siregar B \& Rogers PA 1996 Cytokeratin 8, 18 and 19 in endometrial epithelium of Norplant and norethisterone enanthate injectable progestogen contraceptive users. Human Reproduction 11 (Supplement 2) 144-149.

Wonodirekso S, Affandi B, Siregar B, Barasila AC, Damayanti L \& Rogers PA 2000 Endometrial epithelial integrity and subepithelial reticular fibre expression in progestin contraceptive acceptors. Human Reproduction 15 (Supplement 3) 189-196.

Received 18 February 2008

First decision 22 April 2008

Accepted 21 May 2008 